\title{
Case study of a mesospheric wall event over Ferraz station, Antarctica $\left(62^{\circ} \mathrm{S}\right)$
}

\author{
J. V. Bageston ${ }^{1}$, C. M. Wrasse ${ }^{2}$, R. E. Hibbins ${ }^{3}$, P. P. Batista ${ }^{1}$, D. Gobbi ${ }^{1}$, H. Takahashi ${ }^{1}$, D. C. Fritts ${ }^{5}$, V. F. Andrioli ${ }^{1}$, \\ J. Fechine ${ }^{4}$, and C. M. Denardini ${ }^{1}$ \\ ${ }^{1}$ Instituto Nacional de Pesquisas Espaciais (INPE), São José dos Campos, Brazil \\ ${ }^{2}$ Vale Soluções em Energia (VSE), São José dos Campos, Brazil \\ ${ }^{3}$ British Antarctic Survey (BAS), Cambridge, UK, and Norwegian University of Science and Technology (NTNU), \\ Trondheim, Norway \\ ${ }^{4}$ Universidade Federal de Campina Grande (UFCG), Campina Grande, Brazil \\ ${ }^{5}$ Colorado Research Associates (CoRA), NorthWest Research Associates (NWRA), Boulder, USA
}

Received: 9 July 2010 - Revised: 20 January 2011 - Accepted: 21 January 2011 - Published: 28 January 2011

\begin{abstract}
On 16-17 July 2007 during an observational campaign at Comandante Ferraz Antarctic Station $\left(62^{\circ} \mathrm{S}\right.$, $58^{\circ} \mathrm{W}$ ), a mesospheric wall was observed with an airglow all-sky imager. The wave appeared like an extensive dark region in the all-sky airglow images, with a large depletion in the $\mathrm{OH}$ emission. Simultaneous mesospheric winds measured with a MF radar at Rothera station and temperature profiles from SABER instrument, on board of TIMED satellite, were used to obtain the propagation condition of the wave. Wind measurements during four days, around the time of observation of the wave, are presented in order to discuss the type and consistence of the duct in which this wave was propagating. By using wavelet analysis and tidal amplitude components we found that 12 and $8 \mathrm{~h}$ components were the most important periodicities around the time interval of the wave observation. A collocated imaging spectrometer, for mesospheric temperature measurements, has been operated simultaneously with the all-sky imager. Direct effects of the mesospheric front have been seen in the spectrometric measurements, showing an abrupt decrease in both $\mathrm{OH}$ intensity and rotational temperature when the wave front passes overhead. The main contribution of the present work is the investigation of the type of duct in which the wall event was propagating. We found evidences for a thermal duct structure to support the mesospheric wall propagation. This result was obtained by two types of analysis: (a) the tidal components analysis and winds filtering (harmonic analysis), and (b) comparison between the terms of the $m^{2}$ dispersion relation.
\end{abstract}

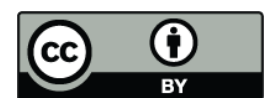

Correspondence to: J. V. Bageston (bageston@gmail.com)
Keywords. Atmospheric composition and structure (Airglow and aurora) - Meteorology and atmospheric dynamics (Middle atmosphere dynamics; Waves and tides)

\section{Introduction}

The mesospheric fronts and specially bore events (Dewan and Picard, 1998), have been extensively reported at low and mid latitudes (Taylor et al., 1995; Smith et al., 2003; Medeiros et al., 2005; Fechine et al., 2005). However, only two studies were reported for high latitudes (Nielsen et al., 2006; Stockwell et al., 2006). Taylor et al. (1995) described a spectacular gravity wave event observed in four mesospheric nightglow emissions at Hawaii $\left(20.8^{\circ} \mathrm{N}\right)$ during the ALOHA-93 campaign. Coincident intensity measurements showed that the front was characterized by a sudden increase in the $\mathrm{OH}$ brightness and a concurrent decrease in the OI emission. Smith et al. (2003) reported a mesospheric bore over southern USA which was visible to the naked eye. Medeiros et al. (2005) and Fechine et al. (2005) have reported a large number of mesospheric front events $(>60)$ over the northeastern Brazilian ( $7^{\circ} \mathrm{S}$ ) sector during a period of two years.

Based on Na lidar, meteor radar and all-sky airglow images, Batista et al. (2002) reported simultaneous observation of sporadic sodium layer, mesospheric winds and wall event at Cachoeira Paulista $\left(23^{\circ} \mathrm{S}\right)$. The sporadic sodium layer they observed had peculiar characteristics regarding to the layer motion and density. They observed a vertical shear in the horizontal wind that was associated with the wall event. Also, Batista et al. (2002) mentioned a rapid decrease in the $\mathrm{OH}(6-2)$ intensity as well in the $\mathrm{OH}$ rotational

Published by Copernicus Publications on behalf of the European Geosciences Union. 
temperature (nominal peak at $87 \mathrm{~km}$ ), and a singular behavior of the rotational temperature of $\mathrm{O}_{2}$ (nominal peak at $94 \mathrm{~km}$ ) that showed a very large increase.

Nielsen et al. (2006) using an all-sky imager at Halley station, Antarctica $\left(75.5^{\circ} \mathrm{S}\right)$, reported the first bore event observed at high latitudes. This wave event was seen in three different airglow layers $\left(\mathrm{OH}, \mathrm{Na}\right.$, and $\left.\mathrm{O}_{2}\right)$ and persisted on the image for a long time $(\sim 3 \mathrm{~h})$. The characteristics of the bore event were determined by applying the S-Transform analysis (Stockwell et al., 2006).

The occurrence of these sorts of events would be associated with a temperature inversion layer that acts as a wave duct. In fact, Smith et al. (2003) and She et al. (2004) firstly reported simultaneous occurrence of the mesospheric bore and temperature inversion layer. Besides that, the most recent model, which explains the mesospheric front phenomena (Dewan and Picard, 1998, 2001), pointed out that ducts may be generated by some combination of wind shear and a temperature inversion layer.

In the recent literature (e.g. Fechine et al., 2009; Narayanan et al., 2009) it could be observed a lack of specific analysis, using spectral and/or harmonic techniques, to find out the types of duct that support the mesospheric fronts, which are required for this kind of waves (Dewan and Picard, 1998; Smith et al., 2003), even though considering the existence of simultaneous observations of winds and temperature.

In the present work we report the observation of a mesospheric front, which was the unique observation in our images data set with the following particularities: (1) presence of a sharp "front-like" that extended along the entire image; (2) as the front passed overhead, a simultaneous sudden decrease in both rotational temperature and $\mathrm{OH}$ intensity was shown by an imaging spectrometer. Zonal and meridional winds were measured by a MF radar at Rothera station $\left(68^{\circ} \mathrm{S}, 68^{\circ} \mathrm{W}\right)$ and temperature profiles were obtained from TIMED/SABER at the surroundings of the Ferraz station. Analysis of the wind in the wave propagation direction gave us evidence to infer that the winds were not responsible for the observed duct, but the thermal condition, i.e., thermal duct. This important result was obtained by applying the least square fitting in the winds and by comparing the terms of the $m^{2}$ equation.

\section{Observation and data analysis}

During an observational campaign (Bageston et al., 2009) focused on characterizing the gravity waves observed at Comandante Ferraz Antarctic Station $\left(62.1^{\circ} \mathrm{S}, 58.4^{\circ} \mathrm{W}\right)$, we have identified three uncommon gravity waves events - the so called mesospheric fronts. The present work will describe and characterize the mesospheric wall event observed on 1617 July 2007 and investigate the propagation condition for such wave, based on the least mean square fitting method applied to the wind time series.

The imaging system used for the observations was an allsky imaging system, that consists of a CCD detector (SBIG, STL-1001E model) with high resolution, $1024 \times 1024$ pixels, $24.6 \times 24.6 \mathrm{~mm}$ and $\sim 50 \%$ of quantum efficiency in the near infrared (NIR). The CCD camera was coupled to a telecentric lens system, a fish eye lens and a 2 inch wide band NIR optical filter $(715-930 \mathrm{~nm})$ with notch at $865.5 \mathrm{~nm}$ to suppress the $\mathrm{O}_{2}(0-1)$ emission. The imaging system has a severe limitation, i.e., the telecentric lens system do not belong to the SBIG camera, and consequently the sky images are generated onto a small portion of the CCD chip, 30\% of the CCD area. Given this constraint, the images were not binned but cropped to $512 \times 512$ pixels keeping the sky image in the center of the image, since the useful image have approximately $312 \times 312$ pixels. This process was done in order to maintain the previous methodology used by other authors to perform the calibration and the data processing (Medeiros et al., 2003; Wrasse et al., 2007). In the calibration process, the images are unwarped by using calibration maps that are projections of plane areas at the height of the observed emission that in this case is $87 \mathrm{~km}$ high (the nominal $\mathrm{OH}$ emission peak). These areas are proportions in $\mathrm{km}$ of the original image in pixels that are $256 \times 256 \mathrm{~km} ; 512 \times 512 \mathrm{~km}$; $768 \times 768 \mathrm{~km}$ and so on. Normally we refer to the projected images as a projection in a given area, which is associated to a resolution, in $\mathrm{km} / \mathrm{pixel}$, that is the projected area (in $\mathrm{km}$ ) divided by the size (in pixels) of the original image. In this case study we choose the projection of $768 \times 768 \mathrm{~km}$ which gives a resolution of $1.5 \mathrm{~km} /$ pixel ( $768 \mathrm{~km} / 512$ pixels), because the wave front appeared more evident and was easer to analyze in comparison with other projections. Since the useful image cover about $312 \times 312$ pixels on the $\mathrm{CCD}$, so the unwarped image projected in $768 \times 768 \mathrm{~km}$ has an effective area of $468 \times 468 \mathrm{~km}$.

The gravity wave parameters were obtained by using the standard 2-D FFT analysis (Garcia et al., 1997; Medeiros et al., 2003; Wrasse et al., 2007). The amplitude and phase of the cross spectrum was obtained by a sequence of $6 \mathrm{im}$ ages, which allows us to calculate the gravity wave horizontal wavelength $\left(\lambda_{h}\right)$, propagation direction $(\phi)$, observed phase speed $\left(c_{\text {obs }}\right)$ and period $\left(\tau_{\text {obs }}\right)$. For more details of the campaign and the first results see Bageston et al. (2009).

\section{The mesospheric wall event}

The mesospheric wall was observed on the night of 16-17 July 2007 at Ferraz station. Figure 1 presents a sequence of three all-sky images of the event observed in $\mathrm{OH}$ emission at 06:00, 06:10 and 06:20 LT, where LT $=\mathrm{UT}-3 \mathrm{~h}$ (at Ferraz). The image at 06:00 LT depicts the first clear view of the wave event. The middle image shows the front almost at the zenith and reveals an enhancement of the front, which 


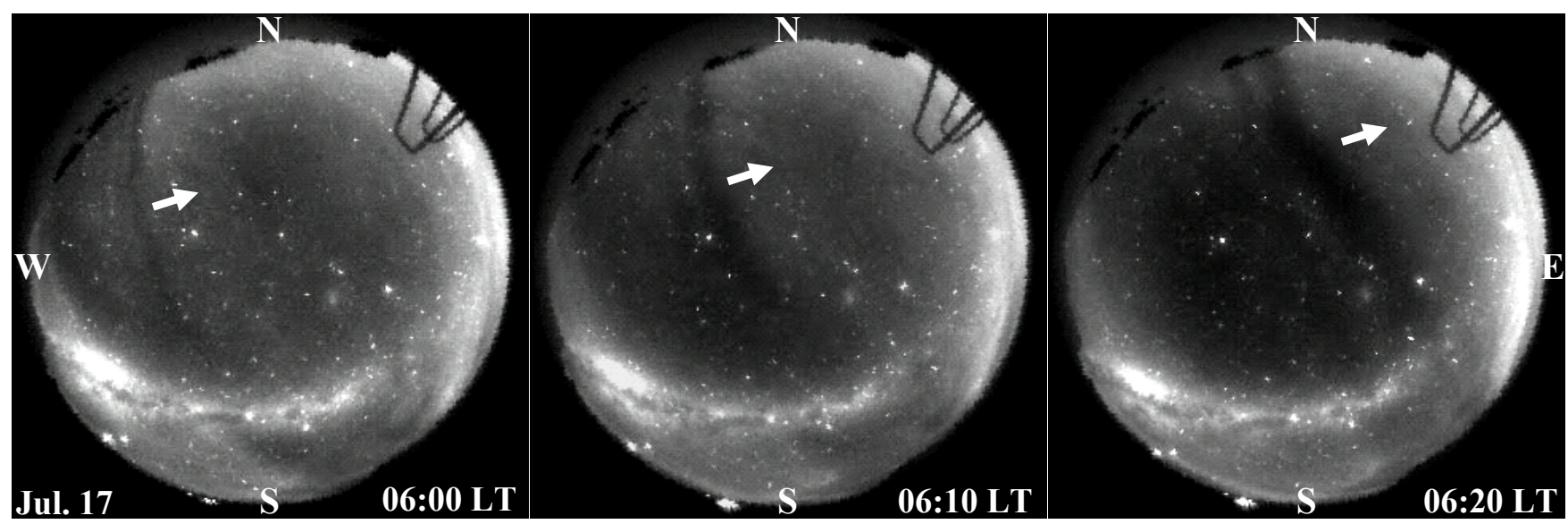

Fig. 1. Three individual all-sky images obtained in the night of 16-17 July 2007 showing a mesospheric front propagating approximately from West to East. The observations time are shown in the right bottom side.

becomes broader than on the first image. The wave event was observed over $1 \mathrm{~h}$ (from 05:50 to 06:50 LT) progressing from horizon to horizon, and showed no signs of dissipation while propagating to the border of the image. The arrows over each image indicate the wave propagation direction. Due to the limitation of the imager, which observes the waves with only one filter (NIR OH), we are not able to infer what is happening in the upper airglow layers.

Figure 2a shows an example of image used in the FFT spectral analysis, with the star field removed and a map projection of $768 \times 768$ pixels. We must emphasize that all the images used in the characterization of the wave were unwarped and the star field was removed previously previously to the application of the FFT analysis. The box drawn in the image defines the area used to characterize the wave. The same characteristics of the box (size and position) are used for all images analyzed in each event (series of images that represent one wave event). The criteria used to choose the size and position of the box is basically defined by the wave event, that is, its dimension and position on the image. In other words, we choose a region where the event is more evident (box position) and the size of the box depends on the dimension of the event, in order to get at least two crests of the wave inside the box. Figure $2 b$ presents a sequence of profiles that represent a relative intensity obtained from the orthogonal line drawn in each image crossing the box. The first profile show a very well defined crest behind the main valley, while from the second profile and so on we can observe two or more crests behind the dark region (minimum in the profiles). The third profile was obtained from the image showed in Fig. 2a. From the profiles showed in Fig. 2b it is possible to identify one main valley, which represents the front of the wall event propagating in the $\mathrm{OH}$ airglow layer. We can also observe a growing in the number of crests (or valleys) behind the main valley, but the hourly rate of this growth was not inferred since we have analyzed less than ten minutes of data, representing the time interval in which the wave appeared clearly. The result of the FFT analysis is summarized in Fig. 2c, through the unambiguous cross spectrum obtained by using of six images.

From the result of the FFT analysis we are able to obtain the gravity wave parameters (Wrasse et al., 2007). For the presented mesospheric event the observed parameters are the following: (a) horizontal wavelength of $35 \mathrm{~km}$; (b) observed period of $8 \mathrm{~min}$; (c) observed phase speed of $71 \mathrm{~m} \mathrm{~s}^{-1}$ and (d) propagation direction at $90^{\circ}$ clockwise from north, i.e., eastward propagation.

\section{The mesospheric environment and the mesospheric wall}

In order to investigate the mesospheric environment during the night of the mesospheric front observation, we take simultaneous measurements of horizontal winds provided by a MF radar at Rothera station (68 $\mathrm{S}$ ) (Jarvis et al., 1999; Hibbins et al., 2007) and temperature profile obtained by the SABER instrument (Russell et al., 1999; Mertens et al., 2004). Also, the $\mathrm{OH}(6-2)$ airglow band intensity and the rotational temperature, simultaneously measured at Ferraz station $\left(62^{\circ} \mathrm{S}\right)$, showed clear effects in both parameters due to the passage of this mesospheric wall.

Figure 3 presents a map showing the location of Ferraz station (EACF: the acronym of Estação Antártica Comandante Ferraz), where an $\mathrm{OH}$ temperature imaging spectrometer and an all-sky $\mathrm{OH}$ airglow imager are in operation, denoted by a red filled box. The concentric circle in Ferraz, with a diameter of $500 \mathrm{~km}$ ( 2 times the radius) is slightly larger than the diameter of the unwarped all-sky image, which have $468 \mathrm{~km}$. Rothera station, where the winds data were taken, is denoted by a filled red triangle, located approximately $800 \mathrm{~km}$ away from Ferraz on the Antarctic Peninsula. The blue dots in the 


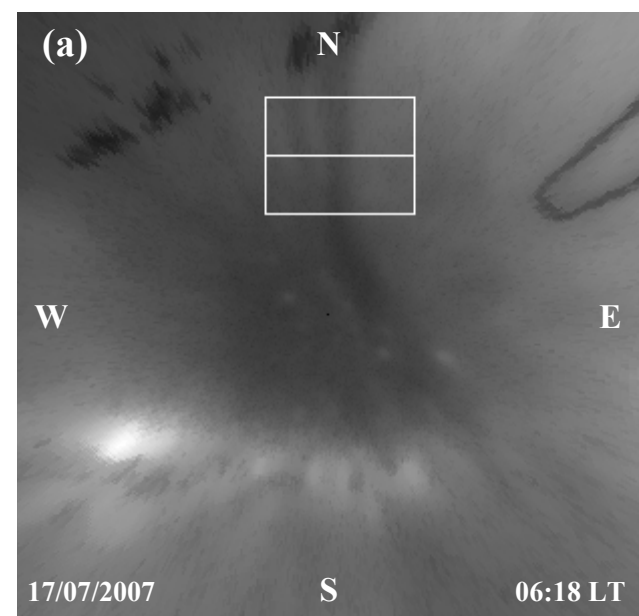

(c) Averaged Cross Spectrum

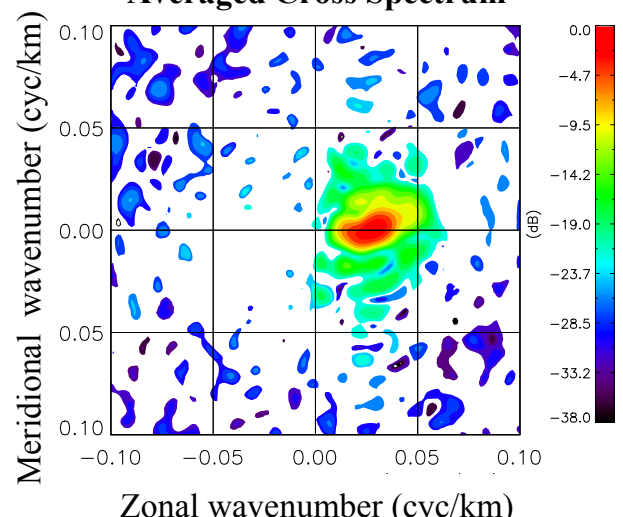

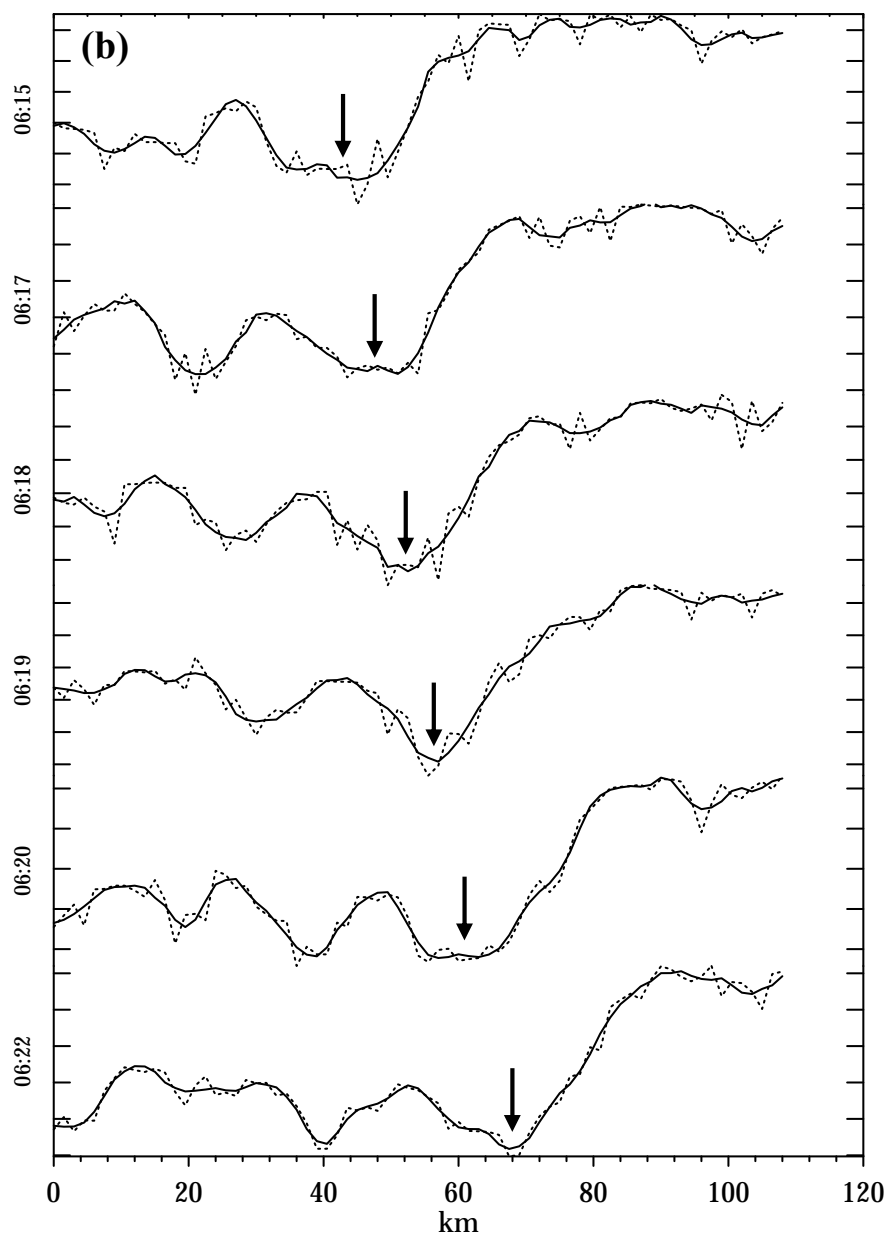

Fig. 2. Analysis of the mesospheric front observed at Ferraz station during the night 16-17 July 2007. (a) One of the images used to obtain the gravity wave parameters. The selected area in the box represents the portion of each image where the FFT analysis was applied. (b) Relative intensity profiles, obtained from a line orthogonal in the wave propagation direction, as indicated in the box drawn in panel (a). (c) Unambiguous cross-spectrum obtained by using of six airglow images.

map are the TIMED/SABER sounding on 16 June, and the hours are in local time. The selected sounding, at 02:09 LT, was chosen for the propagation condition analysis because it was the nearest sounding point to Ferraz, located almost within the field of view of the imager.

\subsection{Vertical propagation condition}

The vertical propagation condition of the mesospheric wall was obtained by the vertical squared wavenumber profile, given by the following gravity wave dispersion relation:

$m^{2}=\left[\frac{N^{2}}{\left(u_{0}-c\right)^{2}}-\frac{u_{0}^{\prime \prime}}{u_{0}-c}-k_{\mathrm{h}}^{2}\right]$,

where, $m$ is the vertical wavenumber, $N^{2}$ is the squared Brunt-Väisälä frequency; $u_{0}$ is the wind velocity in the wave direction and $u_{0}^{\prime \prime}$ is the second derivative of the wind as function of altitude; $c$ is the observed phase speed, and $k_{\mathrm{h}}=2 \pi / \lambda_{h}$ is the horizontal wavenumber.

The dispersion relation given in Eq. (1) is valid for gravity waves propagating in an environment where the effects of wind shear and temperature gradients can not be neglected (Chimonas and Hines, 1986; Isler et al., 1997).

The squared Brunt-Väisälä frequency, $N^{2}$, could be accessed by using the TIMED/SABER temperature profile, using the follow relation:

$N^{2}=\frac{g}{T}\left(\nabla T_{z}+\frac{g}{C_{p}}\right)$,

where $g$ is the acceleration due to gravity, $T$ is the temperature, $C_{p}=1005 \mathrm{~J} \mathrm{~kg}^{-1} \mathrm{~K}^{-1}$ is the specific heat, and $\nabla T_{z}$ the vertical temperature gradient.

The propagation condition for the mesospheric wall event is presented in Fig. 4a, the magnitude of the wind speed in the direction of wave is shown in Fig. 4b and Fig. 4c shows 
the SABER temperature profile. The background wind presented in Fig. $4 \mathrm{~b}$ is a projection of the zonal and meridional wind components in the wave propagation direction (90 clockwise from north), that mean the zonal wind component. The wind components obtained from the MF radar were hourly averaged, and the error bars presented in Fig. 4a and $b$ are related to the variance due to the hourly average. For the purpose of this work, the wind components were vertically interpolated at each $1 \mathrm{~km}$ and three points running averaged in altitude. The SABER profiles were obtained within an area of $30^{\circ} \times 30^{\circ}$ of latitude and longitude, centered at the geographic coordinates of Ferraz station. For each wave event analyzed we used a selection criteria for the TIMED/SABER temperature profile according with a minimum time (LT) difference between the sounding time and the time of observation of the wave event and choosing the closest profile from the observatory, i.e., the shortest distance (in degree) between the observatory and the sounding point (lat., long.). For the SABER temperature profile used here the information are labeled in Fig. 4c.

It is clearly seen from Fig. 4a, that the mesospheric wall is situated in a duct region between 82 and $89 \mathrm{~km}$. A duct in $\mathrm{m}^{2}$ means an interval in which there is a propagating region $\left(\mathrm{m}^{2}>0\right)$, surrounded by evanescent regions $\left(\mathrm{m}^{2}<0\right)$. This characteristic is one of the criteria that define mesospheric fronts, like the event presented in this paper. We must emphasize that the observed duct is within the $\mathrm{OH}$ airglow layer according to SABER observations (Marsh et al., 2006). They observed that the vertical distribution of $\mathrm{OH}$ Meinel emissions and temperatures, in terms of height and magnitude of maximum emission, varies significantly as a function of latitude. They compare the altitude peak of the $\mathrm{OH}$ emission by using SABER observations and predictions from a chemical dynamical model, and it was observed similarities in their results with peak at with peak at $\sim 89 \mathrm{~km}$ around $60^{\circ} \mathrm{S}$ and a wide $\mathrm{OH}$ layer between approximately 85 and $95 \mathrm{~km}$.

\subsection{Mesospheric winds and duct investigation}

Winds play an important role in the gravity wave propagation. Because simultaneous wind data was not available at Ferraz, the MF radar working at a frequency of $1.98 \mathrm{MHz}$ with a transmitter power of $25 \mathrm{~kW}$ (Jarvis et al., 1999; Hibbins et al., 2007) from Rothera was utilized for this study, which was the closest location with available mesospheric winds data. Data used in this study are restricted to altitudes below $94 \mathrm{~km}$ as several authors have observed that MF radars tend to underestimate wind speeds compared to those observed by meteor radars above this altitude (e.g. Manson et al., 2004; Portnyagin et al., 2004).

Figure 5 shows contour plot for the wind in the wave propagation direction, between 12:30 LT of 16 July and 11:30 LT of 17 July 2007. The time of wind measurements was converted to Local Time of Rothera station (UT $-4.5 \mathrm{~h}$ ), so that the phases of the wind perturbations due to the tides

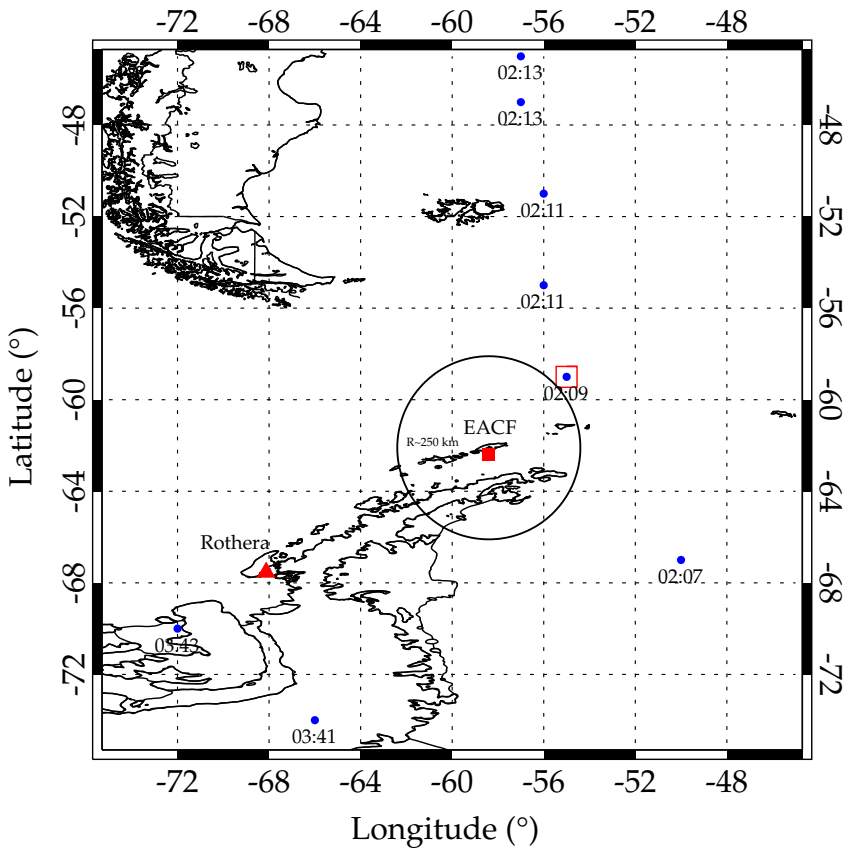

Fig. 3. Geographical map showing the location of the Comandante Ferraz Antarctic Station (EACF) denoted by the red filled box, and Rothera station is denoted by the red filled triangle. The sounding points of the Timed/Saber for 16 July are showed in blue dots and the hours are in Local Time. The nearest sounding of Ferraz is selected in a red box and it was used in the analysis.

match with the time of the all-sky imager observations at Ferraz station with assumption that the tidal motions at this latitude during winter are predominantly sun-synchronous (Murphy et al., 2006). In-turn, we assume that the tides observed over Rothera at mesospheric heights also represent the tidal features over Ferraz. The vertical red dashed lines at 06:15 LT denotes the time when the mesospheric front was seen sharper in the all-sky images. The wind values at this time vary approximately from -20 to $5 \mathrm{~m} \mathrm{~s}^{-1}$ and a reversal of the wind is seen around the time when the mesospheric wall was crossing overhead (06:15 LT).

In order to characterize the tidal periodic oscillations, a Morlet wavelet spectral analysis has been applied to the wind in the wave propagation direction at $86 \mathrm{~km}$ of altitude, from 15 July to 18 July. Figure 6a shows the wavelet power spectra for periods from 4 to $33 \mathrm{~h}$ as a function of time, showing dominant periods close to 8 and $12 \mathrm{~h}$. The full line circled areas indicate a significance level higher than $90 \%$ in the spectral power density. Such periodicities were also present in both zonal and meridional components in the altitude range between 80 and $94 \mathrm{~km}$, and were already reported for Rothera wind observations (Riggin et al., 2003; Hibbins et al., 2007). The original time series of wind and the filtered series are presented in Fig. 6b. The winds were filtered by using the Wavelet pass-band filter, between 6 and $14 \mathrm{~h}$, according to the wavelet results presented in Fig. 6a, in order 

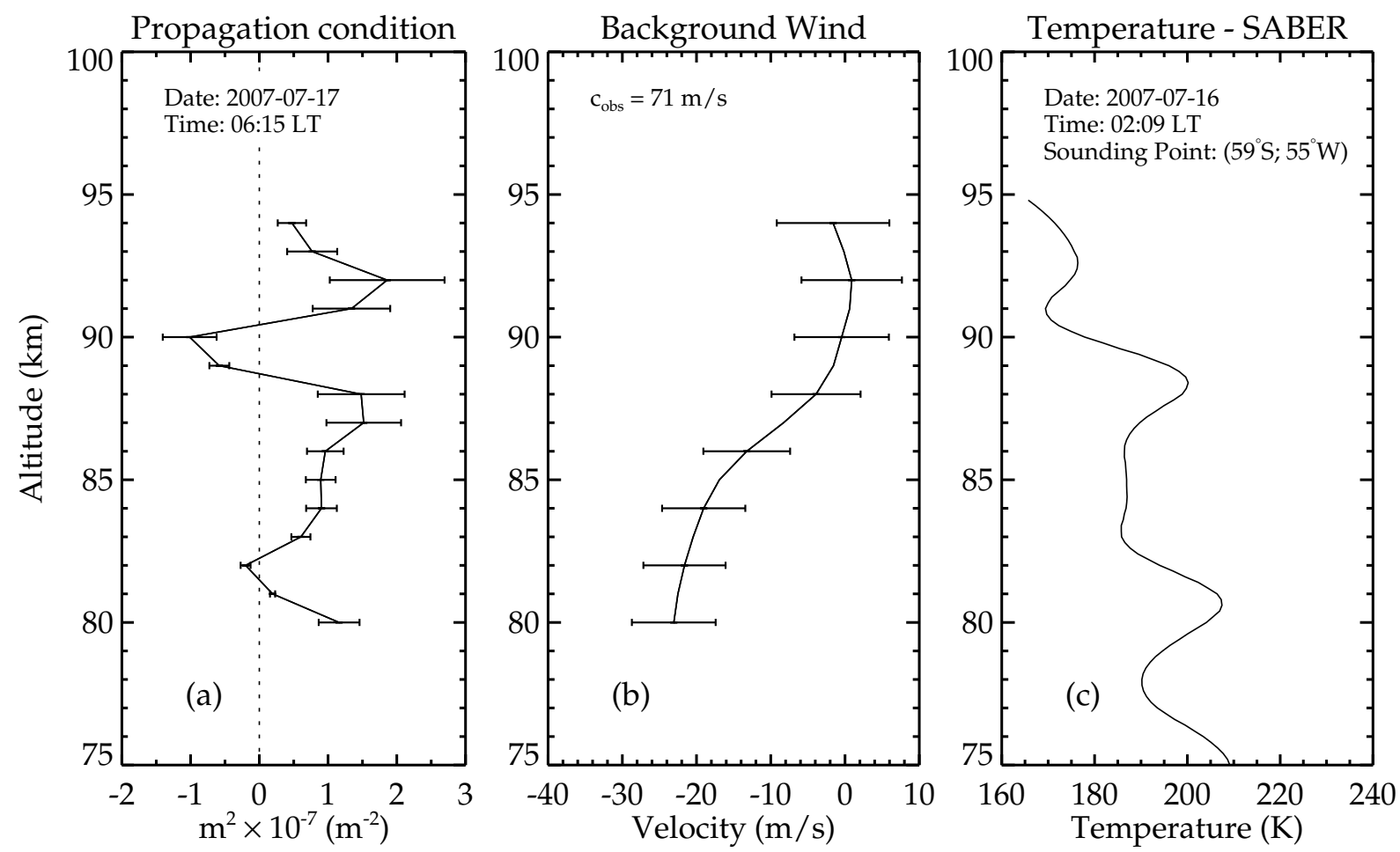

Fig. 4. (a) Vertical squared wavenumber $\left(\mathrm{m}^{2}\right)$, showing a duct region between $\sim 82$ and $\sim 89 \mathrm{~km}$. (b) Hourly wind profile observed by MF radar, between 06:00 and 07:00 LT, in the same propagation direction as the wave front. (c) Kinetic temperature profile obtained by SABER on 16 July 2007.

to compare this result with the original wind. It is possible to observe that the filtered winds fits very well with the original winds, especially near to the time of observation of the wall event, denoted by the vertical dashed lines.

Analogous analyses were performed at the altitudes around $86 \mathrm{~km}$, in the duct region, and similar results were found. Then, the main contributions for the winds variability, in the $\mathrm{OH}$ airglow layer, were the semi-diurnal tide and with less importance the terdiurnal tide.

Tidal periodicities could drive the winds to strong variability, which can lead the mesospheric front to a Doppler duct condition, as reported by Fechine et al. (2009). They showed a mesospheric bore supported by a Doppler duct at equatorial latitude $\left(7^{\circ} \mathrm{S}\right)$. Also, they attributed the Doppler duct to a strong and variable wind profile caused largely by a semi-diurnal tide, however no component wind analysis were showed.

In our observations, it was showed that the wind profile along the wave propagation direction have a well defined behavior without strong variability (Fig. 4b). Even with this behavior, the wind could contribute to the duct showed in Fig. 4a, and would also be supported by the strong tidal oscillations around the observation of the wave (Fig. 6a). By means of the next following analysis we can evaluate the wind contribution for the duct condition in a mesospheric front event.
The goal of this analysis is to identify how the tidal oscillations contribute to the wind variability, and consequently for the $m^{2}$ profile. By using this result we are able to infer if the duct was caused mainly by the wind variability (Doppler duct), or if not, by the Brunt-Väisälä frequency, due the variability in the temperature (thermal duct), or whether the duct can be caused by the combination of these two effects (dual duct). By performing a relative comparison between the terms of the $m^{2}$ dispersion relation (Eq. 1), and with the squared Brunt-Väisälä frequency, $N^{2}$, we are able to infer the relative contribution for the duct condition. However, it must be emphasized that with the method of the harmonic fitting in the winds, as described below, we can infer which tidal component is more important or if a combination of two or more components are responsible for the duct, in the case of a Doppler or dual duct.

The present work uses the least square fitting to access the tidal contribution in the $\mathrm{m}^{2}$ profile. The least square fitting makes use of the well established classical harmonic equation used for wind analysis:

$$
\begin{aligned}
V(h, t)= & V_{0}+V_{1} \cos \left(\frac{2 \pi}{24}\left(t-\phi_{1}\right)\right) \\
& +V_{2} \cos \left(\frac{2 \pi}{12}\left(t-\phi_{2}\right)\right)+V_{3} \cos \left(\frac{2 \pi}{8}\left(t-\phi_{3}\right)\right),
\end{aligned}
$$




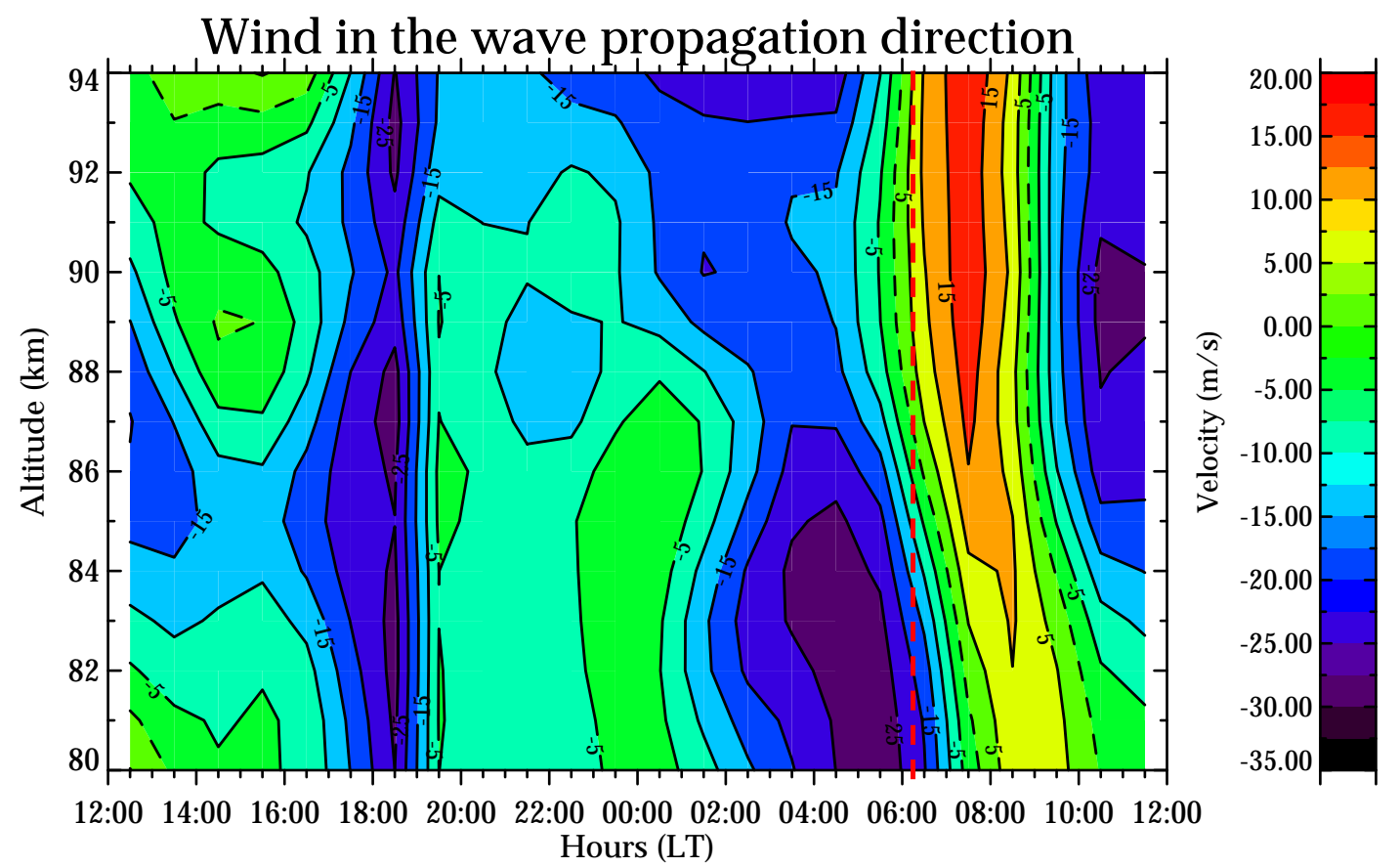

Fig. 5. Contour plots of wind in the wave propagation direction.

In the above equation, $V_{0}$ represents the mean wind, $V_{1}$ is the diurnal tidal amplitude, $\phi_{1}$ is the phase of the diurnal tidal, $V_{2}$ is the semi-diurnal tidal amplitude, $\phi_{2}$ is his phase, $V_{3}$ is the terdiurnal tidal amplitude and $\phi_{3}$ is the respective phase. The time $t$ is measured in days and $h$ is the altitude levels, measured in $\mathrm{km}$. The altitude dependence on the right hand of the Eq. (3) is implicit, since this equation is applied for each altitude level of the radar measurements.

In this work the harmonic fitting, represented by Eq. (3), was applied to the wind data considering only the semidiurnal and ter-diurnal tidal periodicities. Since the wavelet analysis did not show any spectral contribution of diurnal tide, only mean wind, semi-diurnal and ter-diurnal components (amplitudes and phases) were used to obtain the bestfit modeled wind profiles. These fitted wind profiles were used to obtain the new $\mathrm{m}^{2}$ profiles, and then compared to that obtained with the original wind. Figure 7 shows the results obtained.

Figure 7 shows the results obtained by the harmonic fitting applied to the observed wind as shown in Fig. 5, the terms of the Eq. (1) and the squared Brunt-Väisälä frequency. Figure 7a shows that the observed wind and the filtered wind have produced very similar duct conditions. Therefore, in the case presented here the tides did not have an influence on the duct formation. A comparative analysis between the profiles showed in Fig. 7c and d reveals that the Brunt-Väisälä term and the squared Brunt-Väisälä are much greater than the wind terms. This result together with the small difference between $\mathrm{m}^{2}$ profiles estimated by using of different wind conditions show that the observed duct was caused by the vari- ability in the temperature profile (thermal duct) or also could be called Brunt-Väisälä duct.

The mesospheric front characterized in this work was classified as a mesospheric wall due its morphologic characteristics, i.e., a large depletion in the $\mathrm{OH}$ airglow emission, followed by a wide dark region that extended in almost all the field of view of the imager. As would be expected, this mesospheric front was supported by a duct condition which allows the wave to propagate for a long distance. The investigated duct occurrence shows it to be associated with the thermal conditions rather than winds. This type of gravity wave has been reported for the first time for Antarctic latitudes.

We must point out that if we had winds with a higher temporal resolution, for example $10 \mathrm{~min}$, the wind contribution for the duct could be verified. However, it is not possible to obtain the winds with high resolution and simultaneously keep a reasonable accuracy. This fact is due to the radar technique limitations itself. Even using the hourly winds, it is possible to identify the wind contribution for the duct. Meanwhile, in this study only the thermal structure explains the observed duct.

\subsection{Rotational temperature and $\mathrm{OH}$ intensity}

A co-located imaging spectrometer designed to obtain the $\mathrm{OH}(6-2)$ rotational temperature and band intensity was operated simultaneously on the night of the observed mesospheric front. The spectrometer observes the $\mathrm{OH}(6-2)$ emission through an annular field of view of $22.6^{\circ}$ centered at the 


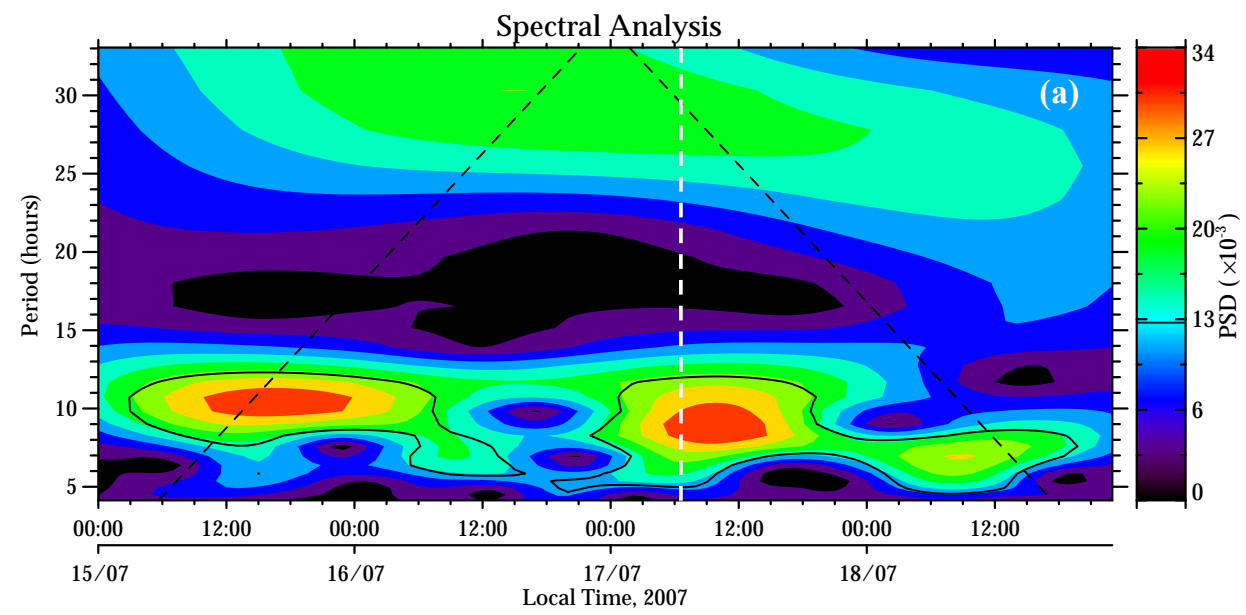

Wind in the wave propagation direction, $\mathrm{h}=86 \mathrm{~km}$

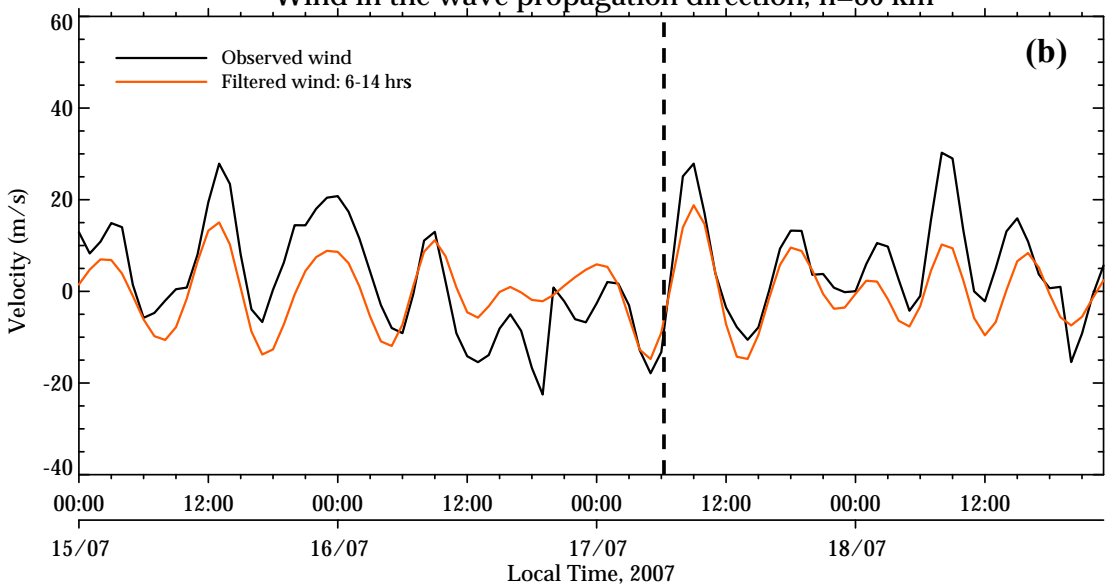

Fig. 6. (a) Spectral analysis obtained by the wavelet technique applied to the original wind time series, projected along the wave, as showed in the panel (b) in black. (b) Time series of the original wind projected in the wave propagation direction (black), for the high of $86 \mathrm{~km}$, together with the filtered wind for the periods between 6 and 14 h, i.e., the typical oscillations showed in the panel (a).

zenith, which provides an observed area of $36 \mathrm{~km}$ radius at altitude of $87 \mathrm{~km}$ (Bageston et al., 2007).

Figure 8 shows the rotational temperature (a) and $\mathrm{OH}(6-$ 2) band intensity (b), with two-minute resolution during the entire night of 16-17 July 2007. Previously to the dark front passage, it was observed an enhancement in both $\mathrm{OH}$ intensity (04:45 LT) and rotational temperature (05:15 LT). When the dark front appears on the field of view of the imaging spectrometer, the $\mathrm{OH}$ intensity (at first) and the temperature started to decrease very quickly. At the moment that the front crosses the zenith (about 06:15 LT) both temperature and $\mathrm{OH}$ intensity fall abruptly. The temperature decreased by $\sim 30$ while the intensity fell by $\sim 74 \%$. These decreases are indicated by the arrows in Fig. 8. It should be observed that the decrease in $\mathrm{OH}$ emission (spectrometric measurements) is in agreement with the front seen in the all-sky images, i.e., a dark region seen in the same airglow emission. $\mathrm{OH}$ intensity fall abruptly.
Similar wave measurements were reported from low latitudes during ALOHA-93 campaign with spectrometric and imaging measurements on 10 October 1993 from Maui $\left(20.8^{\circ} \mathrm{N}\right)$ (Taylor et al., 1995). They observed a sudden increase in both $\mathrm{OH}$ intensity and its rotational temperature when a white sharp front (in the $\mathrm{OH}$ emission), followed by several waves crests, passed overhead. Besides, Taylor et al. (1995) showed a reversal in contrast of the wave pattern in the images of NIR OH and OI $(557.7 \mathrm{~nm})$, i.e., the disturbance appeared brighter in the $\mathrm{OH}$ but darker in the $\mathrm{OI}$. Further, Batista et al. (2002) presented $\mathrm{OH}$ and OI(557.7 nm) all-sky images and photometric measurements at Cachoeira Paulista $\left(22.5^{\circ} \mathrm{S}\right)$ on 13-14 July 1999 . They showed a rapid decrease in $\mathrm{OH}(6-2)$ intensity when the dark front (in $\mathrm{OH}$ images) passed overhead (23:45 LT), but not show a noticeable change in $\mathrm{OH}$ rotational temperature at the same time. However, they mentioned a large increase $(\sim 40 \mathrm{~K})$ in the $\mathrm{O}_{2}$ rotational temperature (nominal peak at $94 \mathrm{~km}$ ) during the passage of the front over the zenith. In our observations it 

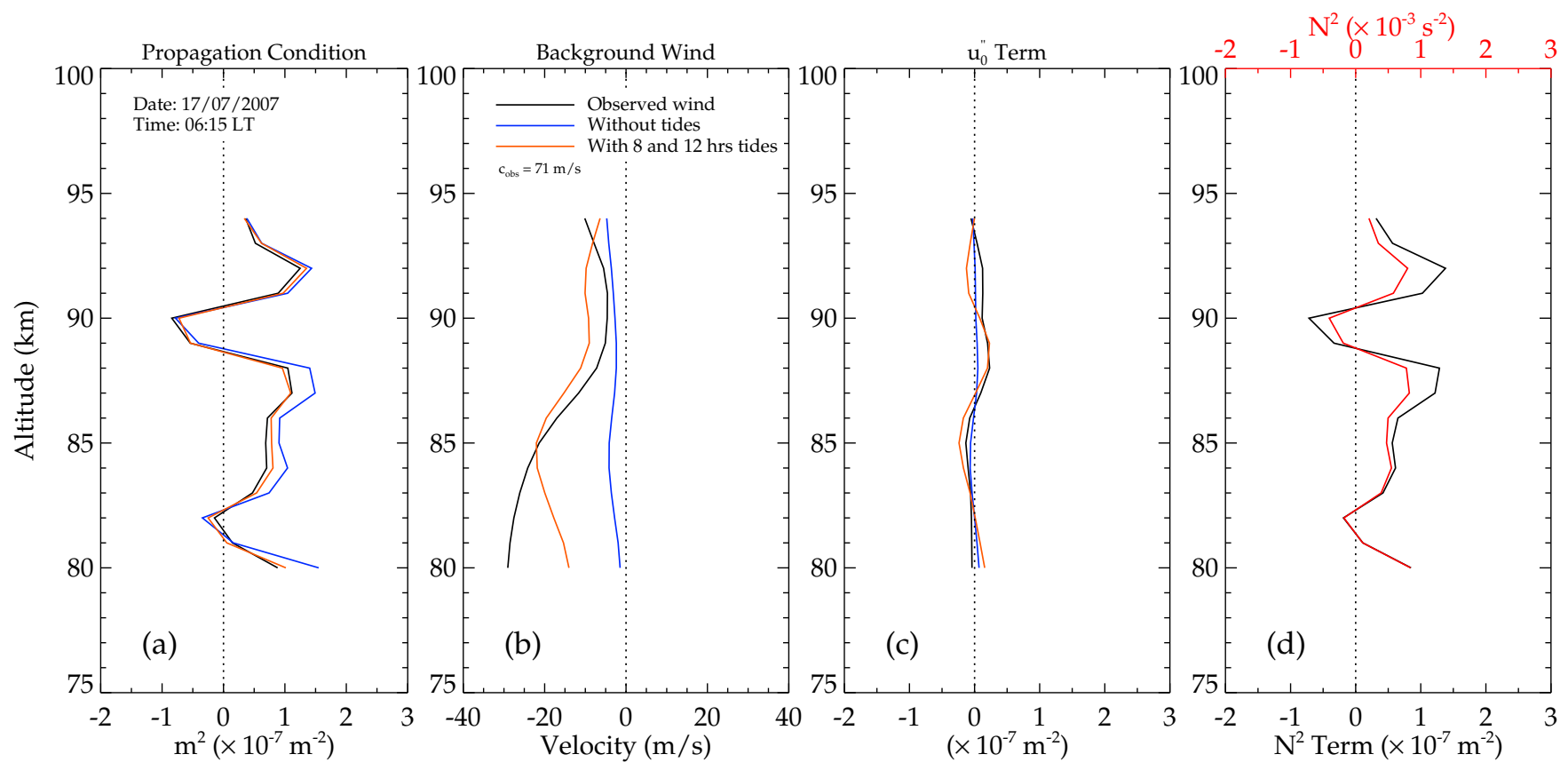

Fig. 7. (a) Vertical propagation condition for the different wind profiles, according with different wind conditions. (b) Observed wind, mean wind (without tidal components) and tidal winds (mean wind plus the components of 8 and $12 \mathrm{~h}$ ). (c) Terms of the second derivative winds, i.e., the second term in Eq. (1). (d) Squared Brunt-Väisälä frequency, $N^{2}$, and its associated term in Eq. (1).
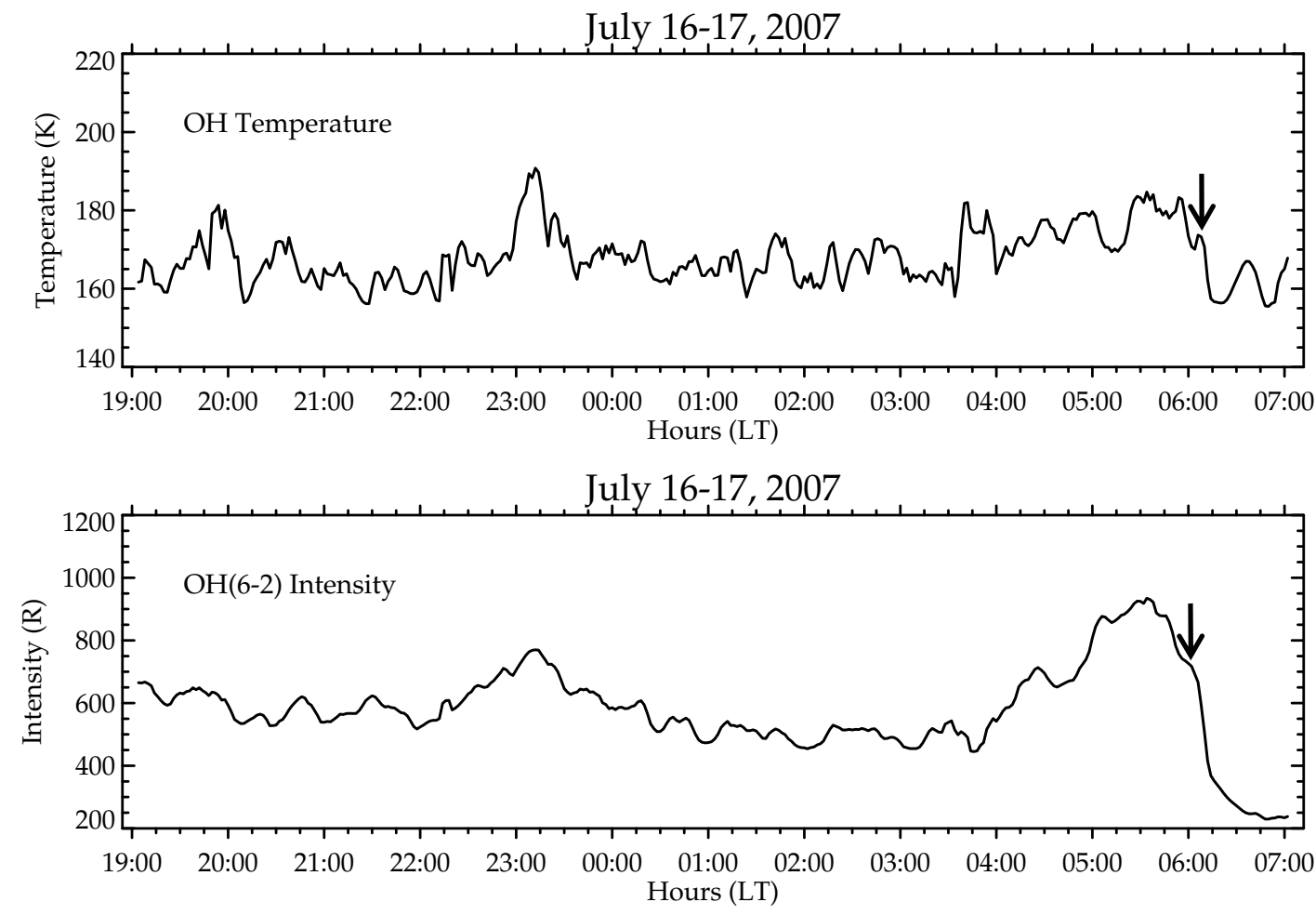

Fig. 8. Rotational temperature of the $\mathrm{OH}(6-2)$ emission and its band intensity, observed at Ferraz by an imaging spectrometer on 16-17 July 2007. 
was very clear the effect of the dark region front overhead the imaging spectrometer. No other event observed at Ferraz station during 2007 caused such depletion in the rotational temperature or $\mathrm{OH}$ band intensity.

\section{Summary}

During an observational campaign at Ferraz station in the wintertime of 2007, an uncommon mesospheric front was observed on the night of 16-17 July. The main results presented in this work are the following: (a) we report first measurements of mesospheric wall over Antarctica; (b) analysis show the observed mesospheric front was supported by thermal duct; (c) the effects of this front was noted in $\mathrm{OH}$ rotational temperature and band intensity. The case study of a mesospheric wall reported in this paper is the first well characterized mesospheric front event over the Antarctic Peninsula. Meanwhile, the main contribution of this work is the application of the well established method of the harmonic fitting used for wind analysis to obtain the information regarding to the duct condition in which a mesospheric front is propagating. In the present case study we obtained strong support, from the winds and $m^{2}$ dispersion relation analyses, for Brunt-Väisälä frequency contribution to the duct in which the mesospheric wall was propagating. This condition was associated to the thermal structure, since were not observed notable differences in the $m^{2}$ profiles obtained for the following wind conditions: (a) the observed wind, (b) the mean wind (without tides), and (c) the wind reconstructed with the main tidal oscillations (with 8 and $12 \mathrm{~h}$ tides). The role of the horizontal winds and its contribution for a duct condition in a mesospheric front can be inferred by using the methodology presented here. Comparative analysis between the terms of the dispersion relation (Eq. 1), has confirmed the contribution of the Brunt-Väisälä $(N)$ term for the duct configuration. Future studies will focus on characterizing other mesospheric fronts observed at Ferraz station, and identify the likely gravity wave sources around the Antarctic Peninsula.

\section{Supplementary material related to this article is available online at: http://www.ann-geophys.net/29/209/2011/ angeo-29-209-2011-supplement.zip.}

Acknowledgements. The present research combines results of the NCT-APA (CNPq process no. 574018/2008-5, FAPERJ process no. E-26/170.023/2008) in the project "Study of the Mesosphere, Stratosphere and Troposphere over Antarctica and its connections with the Southern America (ATMANTAR)", under process no. 52.0182/2006-5, Proantar/MCT/CNPq. The authors thank the Secretariat of the Interministerial Commission for the Resources of the Sea (SECIRM). The Rothera MF radar was jointly supported by National Science Foundation grant OPP-0438777 and by the
UK Natural Environment Research Council. We thank also the TIMED/SABER team and M. G. Mlynczak and J. M. Russell for providing the SABER data. Wavelet software used in the present work was provided by $\mathrm{C}$. Torrence and $\mathrm{G}$. Compo and is available at http://paos.colorado.edu/research/wavelets/. J. V. Bageston thanks to CNPq for post-doctorate project, process no. 151593/2009-4, and also to FAPESP, process no. 2010/06608-2, for the support during the time expended for the corrections on this paper. C. M. Denardini and C. M. Wrasse thank to CNPq for the grants 305923/2008-0 and 304277/2008-8, respectively.

Topical Editor C. Jacobi thanks A. Semenov and A. Taori for their help in evaluating this paper.

\section{References}

Bageston, J. V., Gobbi, D., Takahashi, H., and Wrasse, C. M.: Development of Airglow OH Temperature Imager for Mesospheric Study, http://www.scielo.br/, Braz. J. Geophys., 25(2), 27-34, 2007.

Bageston, J. V., Wrasse, C. M., Gobbi, D., Takahashi, H., and Souza, P. B.: Observation of mesospheric gravity waves at Comandante Ferraz Antarctica Station (62 ${ }^{\circ}$ S), Ann. Geophys., 27, 2593-2598, doi:10.5194/angeo-27-2593-2009, 2009.

Batista, P. P., Clemesha, B. R., Simonich, D. M., Taylor, M. J., Takahashi, H., Gobbi, D., Batista, I. S., Buriti, R. A., and Medeiros, A. F.: Simultaneous lidar observation of a sporadic sodium layer, a "wall" event in the $\mathrm{OH}$ and OI5577 airglow images and the meteor winds, J. Atmos. Sol-Terr. Phys., 64, 1327-1335, 2002.

Chimonas, G. and Hines, C. O.: Doppler Ducting of Atmospheric Gravity-Waves, J. Geophys. Res., 91, 1219-1230, 1986.

Dewan, E. and Picard, R.: Mesospheric bores, J. Geophys. Res., 103, 6295-6305, 1998.

Dewan, E. M. and Picard, R. H.: On the origin of mesospheric bores, J. Geophys. Res., 106, 2921-2928, 2001.

Fechine, J., Medeiros, A. F., Buriti, R. A., Takahashi, H., and Gobbi, D.: Mesospheric bore events in the equatorial middle atmosphere, J. Atmos. Sol-Terr. Phys., 67, 1774-1778, 2005.

Fechine, J., Wrasse, C. M., Takahashi, H., Medeiros, A. F., Batista, P. P., Clemesha, B. R., Lima, L. M., Fritts, D., Laughman, B., Taylor, M. J., Pautet, P. D., Mlynczak, M. G., and Russell, J. M.: First observation of an undular mesospheric bore in a Doppler duct, Ann. Geophys., 27, 1399-1406, doi:10.5194/angeo-271399-2009, 2009.

Garcia, F. J., Taylor, M. J., and Kelly, M. C.: Two-dimensional spectral analysis of mesospheric airglow data, Appl. Optics, 36(29), 7374-7385, 1997.

Hibbibs, R. E., Espy, M. J., Jarvis, M. J., Riggin, D. M., and Fritts, D. C.: A climatology of tides and gravity wave variance in the MLT above Rothera, Antarctica obtained by MF radar, J. Atmos. Sol-Terr. Phys., 69, 578-588, 2007.

Isler, J. R., Taylor, M. J., and Fritts, D. C.: Observational evidence of wave ducting and evanescence in the mesosphere, J. Geophys. Res., 102(D22), 26301-26313, 1997.

Jarvis, M. J., Jones, G. O. L., and Jenkins, B.: New initiatives in observing the Antarctic mesosphere, Adv. Space Res., 24(5), 611619, 1999.

Manson, A. H., Meek, C. E., Hall, C. M., Nozawa, S., Mitchell, N. J., Pancheva, D., Singer, W., and Hoffmann, P.: Mesopause dynamics from the scandinavian triangle of radars within 
the PSMOS-DATAR Project, Ann. Geophys., 22, 367-386, doi:10.5194/angeo-22-367-2004, 2004.

Marsh, D. R., Smith, A. K., Mlynczak, M. G., and Russell III, J. M.: SABER observations of the $\mathrm{OH}$ Meinel airglow variability near the mesopause, J. Geophys. Res., 111, A10S05, doi:10.1029/2005JA011451, 2006.

Medeiros, Taylor, M. J., Takahashi, H., Batista, P. P., and Gobbi, D.: An Investigation of gravity wave activity in the low-latitude upper mesosphere: propagation direction and wind filtering, J. Geophys. Res., 108(D14), 4411, doi:10.1029/2002JD002593, 2003.

Medeiros, A., Fechine, J., Buriti, R., Takahashi, H., Wrasse, C., and Gobbi, D.: Response of OH, O2 and OI5577 airglow emissions to the mesospheric bore in the equatorial region of Brazil, Adv. Space Res., 35, 1971-1975, 2005.

Mertens, C. J., Schmidlin, F. J., Goldberg, R. A., Remsberg, E. E., Pesnell, W. D., Russell III, J. M., Mlynczak, M. G., LópezPuertas, M., Wintersteiner, P. P., Picard, R. H., Winick, J. R., and Gordley, L. L.: SABER observations of mesospheric temperatures and comparisons with falling sphere measurements taken during the 2002 Summer MaCWAVE campaign, Geophys. Res. Lett., 31, L03105, doi:10.1029/2003GL018605, 2004.

Murphy, D. J., Forbes, J. M., Walterscheid, R. L., Hagan, M. E., Avery, S. K., Aso, T., Fraser, G. J., Fritts, D. C., Jarvis, M. J., McDonald, A. J., Riggin, D. M., Tsutsumi, M., and Vincent, R. A.: A climatology of tides in the Antarctic mesosphere and lower thermosphere, J. Geophys. Res., 111, D23104, doi:10.1029/2005JD006803, 2006.

Narayanan, V. L., Gurubaran, S., and Emperumal, K.: A case study of a mesospheric bore event observed with an all-sky airglow imager at Tirunelveli $\left(8.7^{\circ} \mathrm{N}\right)$, J. Geophys. Res., 114(D6), D08114, doi:10.1029/2008JD010602, 2009.

Nielsen, K., Taylor, M. J., Stockwell, R., and Jarvis, M.: An unusual mesospheric bore event observed at hight latitudes over Antarctica, Geophys. Res. Lett., 33, L07803, doi:10.1029/2005GL025649, 2006.

Portnyagin, Y. I., Solovjova, T. V., Makarov, N. A., Merzlyakov, E. G., Manson, A. H., Meek, C. E., Hocking, W., Mitchell, N., Pancheva, D., Hoffmann, P., Singer, W., Murayama, Y., Igarashi, K., Forbes, J. M., Palo, S., Hall, C., and Nozawa, S.: Monthly mean climatology of the prevailing winds and tides in the Arctic mesosphere/lower thermosphere, Ann. Geophys., 22, 33953410, doi:10.5194/angeo-22-3395-2004, 2004.
Riggin, D. M., Meyer, C. K., Fritts, D. C., Jarvis, M. J., Murayama, Y., Singer, W., Vincent, R. A., and Murphy, D. J.: MF radar observations of seasonal variability of semidiurnal motions in the mesosphere at high northern and southern latitudes, J. Atmos. Sol-Terr. Phys., 65, 483-493, 2003.

Russell III, J. M., Mlynczak, M. G., Gordley, L. L., Tansock, J., and Esplin, R.: An overview of the SABER experiment and preliminary calibration results, in: Proceedings of the SPIE, 44th Annual Meeting, Denver, Colorado, 18-23 July 1999, 277-288, 1999.

She, C. Y., Li, T., Williams, B. P., Yuan, T., and Picard, R. H.: Concurrent $\mathrm{OH}$ imager and sodium temperature/wind lidar observation of a mesopause region undular bore event over Fort Collins/Platteville, Colorado, J. Geophys. Res., 109, 2210722115, 2004.

Smith, S. M., Taylor, M. J., Swenson, G. R., She, C., Hocking, W., Baumgardner, J., and Mendillo, M. A.: Multidiagnostic investigation of the mesospheric bore phenomenom, J. Geophys. Res., 108, 13-20, 2003.

Stockwell, R., Taylor, M. J., Nielsen, K., and Jarvis, M. A.: A novel joint space-wavenumber analysis of an unusual Antarctic gravity wave event, Geophys. Res. Lett., 33, L08805, doi:10.1029/2005GL025660, 2006.

Taylor, M. J., Turnbull, D. N., and Lowe, R. P.: Spectrometric and imaging measurements of a spectacular gravity wave event observed during the ALOHA-93 campaign, Geophys. Res. Lett., 20, 2849-2852, 1995.

Wrasse, C. M., Takahashi, H., Medeiros, A. F., Lima, L. M., Taylor, M. J., Gobbi, D., and Fechine, J.: Determinação dos parâmetros de ondas de gravidade através da análise espectral de imagens de aeroluminescência, http://www.scielo.br/, Braz. J. Geophys., 25, 257-266, 2007. 